\title{
Role of Dislocation Rearrangement in the Elastic Modulus Recovery of Deformed Copper
}

\author{
By Masahiro Koiwa* and Ryukiti R. Hasiguti**
}

\begin{abstract}
The elastic modulus recovery and the creep recovery of zone-refined copper specimens were examined after torsional deformation at $-195^{\circ} \mathrm{C}$. The isochronal annealings were performed over the temperature range from $-155^{\circ}$ to $+160^{\circ} \mathrm{C}$. Two specimens, one annealed at $700^{\circ} \mathrm{C}$ and the other at $250^{\circ} \mathrm{C}$ prior to torsional deformation, showed distinct differences in their recovery behaviors. The role of dislocation rearrangements in the elastic modulus recovery was discussed for these two spocimens. In the former, the pinning of dislocations by point defects may be a main mechanism, while in the latter dislocation rearrangements seem to play an important role.
\end{abstract}

(Received November 11, 1966)

\section{Introduction}

It has been known that when metals are plastically deformed the internal friction increases and the apparent elastic modulus decreases. A considerable part of the changes in these quantities recovers rather rapidly than most other mechanical properties. These rapidly recoverable parts of the changes in internal friction and modulus defect are usually called the Köster effect(1). The annealing of the Koster effect has been attributed alternatively to the pinning of dislocations by point defects or to the dislocation. rearrangements.

Granato, Hikata and Lücke(2) analyzed the data of Gordon and Nowick(3) for rock salt and of Smith(4) for copper, and concluded that the annealing of the Koster effect was considered to be due to the point defect migration to dislocations.

On the other hand, the dislocation rearrangement model has not been compared with experimental results, partly because of the lack of quantitative formulation of the process.

The plastically deformed metals, however, usually exhibit creep recovery (or plastic after-effects) after the release of applied stress, which has been interpreted to be due to dislocation rearrangements ${ }^{(5)}$. Therefore it may be expected that the simultaneous measurement of creep recovery and modulus recovery on a plastically deformed metal provides some information as to the role of dislocation rearrangements for the annealing of the Köster effect.

In the present paper, the result of such a measurement on copper specimens will be reported.

* Department of Metallurgy, University of Tokyo, Bunkyo-ku, Tokyo. Now at: The Research Institute for Iron, Steel and Other Metals, Tohoku University, Sendai, Japan.

** Department of Metallurgy, University of Tokyo, Tokyo and the Institute of Physical and Chemical Research, Tokyo, Japan.

(1) A.S. Nowick: J. Appl. Phys., 25 (1954), 1129.

(2) A. Granato, A. Hikata and K. Lücke : Acta Met., 6 (1958), 470.

(3) R.B. Gordon and A.S. Nowick : Acta Met., 4 (1956), 514.

(4) A.D.N. Smith : Phil. Mag., 44 (1953), 453.

(5) M. Koiwa and R.R. Hasiguti : Acta Met., 13 (1965), 673.

\section{Specimens and Experimental Procedure}

Specimens were prepared from zone-refined copper which has been designated as $\mathrm{Z} 4$ in a previous paper ${ }^{(6)}$. After drawing to a diameter of $0.5 \mathrm{~mm}$ without intermediate annealing, one specimen was annealed at $700^{\circ} \mathrm{C}$ and the other at $250^{\circ} \mathrm{C}$, for $1 \mathrm{hr}$ in vacuum. The annealing at $250^{\circ} \mathrm{C}$ was known to be sufficient to complete recrystallization according to observations by optical microscopy. The reason for selecting these annealing temperatures was that some different behaviors can be expected during the elastic modulus recovery as the specimens annealed at the above two temperatures exhibited a striking contrast in creep recovery ${ }^{(5)}$.

The apparatus used is an inverted torsion pendulum, with the details which have been reported elsewhere(7). The annealed specimen is fixed in the torsion pendulum and is deformed by twisting at $-195^{\circ} \mathrm{C}(10 \%$ in surface shear strain). Following the deformation, isochronal annealing studies have been carried out from $-155^{\circ} \mathrm{C}$ to $+160^{\circ} \mathrm{C}$ by $15-\min$ pulses at intervals of $15^{\circ} \mathrm{C}$. The period of vibration $T$, which is related to the elastic modulus $G$ by the equation $T \propto G^{-1 / 2}$, is measured at $-155^{\circ} \mathrm{C}$ after each pulse annealing. As the temperature $-155^{\circ} \mathrm{C}$ is situated between the temperatures of the Bordoni peak and the $P_{1}$ peak at frequencies around 1c/s, the modulus defect at this temperature may be attributed to dislocations responsible for the Bordoni peak and the Niblett-Wilks peak and to other dislocations mobile at still lower temperatures.

The creep recovery of a twisted specimen is measured from the zero point drift on the scale in the optical lever system.

\section{Results and Discussions}

Figs. 1 and 2 show the change in the period of vibration for the $700^{\circ} \mathrm{C}$ and the $250^{\circ} \mathrm{C}$ annealed specimen, respectively. The upper curves in both figures correspond to the measurement at each tem-

(6) M. Koiwa and R.R. Hasiguti : Acta Met., 11 (1963), 1215.

(7) S. Okuda and R.R. Hasiguti : Acta Met., 11 (1963), 257. 


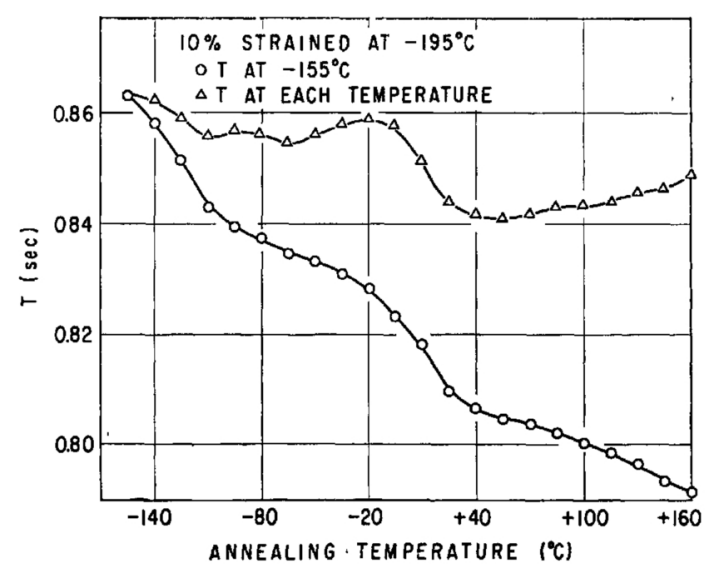

Fig. 1 The recovery of the pəriod of vibration of deformed coppэr (annealed at $700^{\circ} \mathrm{C}$ after drawing).

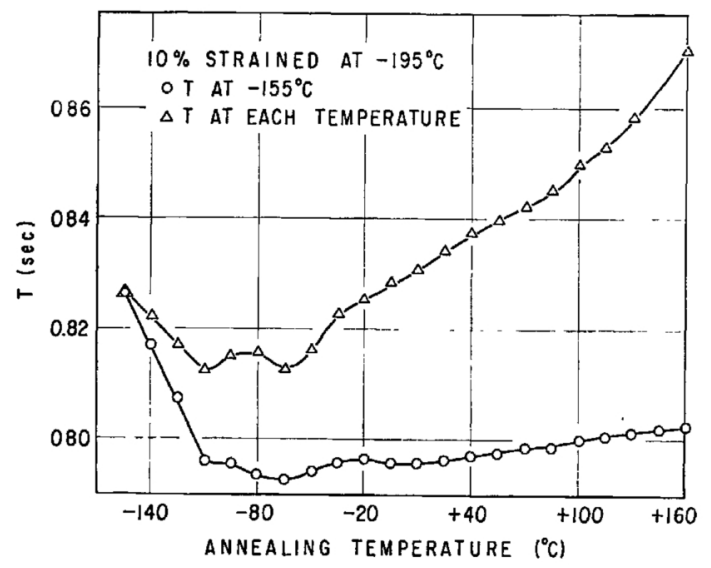

Fig. 2 The recovery of the period of vibration of deformed copper (annealed at $250^{\circ} \mathrm{C}$ after drawing).

perature after each annealing pulse and are shown for comparison. The lower curves obtained by the measurements at $-155^{\circ} \mathrm{C}$ after each annealing pulse are the ones which we are interested in. The upper curves are quite complicated because of the existence of a few relaxation peaks which grow and decay over the temperature range examined ${ }^{(6)}(7)$. Hence, they will not be discussed here in any detail. The internal friction measured will not be shown here, because the modulus defect is more suitable as a measure of the annealing of the Köster effect( ${ }^{(8)}$.

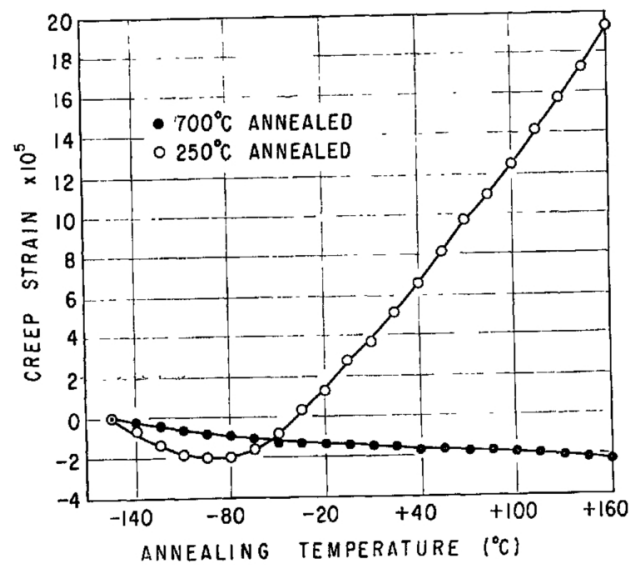

Fig. 3 Creep recovery of the spacimens of Figs. 1 and 2. Negative strain means untwisting or normal aftereffect.

(8) B.M. Mecs and A.S. Nowick : Acta Met., 13 (1965), 771 .
Fig. 3 shows the total amounts of creep recovery after each annealing pulse simultaneously measured on the same specimens as those in Figs. 1 and 2.

The elastic modulus recovery of the $700^{\circ} \mathrm{C}$ annealed specimen shown in Fig. 1 is quite similar to that reported by Lems ${ }^{(9)(10)}$, and exhibits fairly distinct stages (Hereafter, the term "elastic modulus" will be used instead of "the period of vibration", because they are related to each other by a simple relation as described above.). In contrast, the creep recovery shown in Fig. 3 by the closed circles seems not to show any distinct stages corresponding to those in the elastic modulus recovery, although the smallness of the absolute magnitude of creep recovery makes it difficult to deduce a definite conclusion.

The feature of the elastic modulus recovery of the $250^{\circ} \mathrm{C}$ annealed specimen shown in Fig. 2 is considerably different from that of the $700^{\circ} \mathrm{C}$ annealed one. After the initial rapid increase of elastic modulus up to $-110^{\circ} \mathrm{C}$, which is the only similarity to the case of the $700^{\circ} \mathrm{C}$ annealed one, a gradual decrease occurred over a wide temperature range. This phenomenon implies that dislocations become more mobile as the annealing proceeds. This is a reversed tendency from that usually considered as "the annealing of the Köster effect".

The creep recovery of this specimen also exhibits a quite strange feature as can be seen from Fig. 3. The normal recovery (untwisting) ceases around $-80^{\circ} \mathrm{C}$ and the abnormal recovery (retwisting) occurs actively at higher temperatures. The fact that both the elastic modulus recovery and the creep recovery of this specimen change their signs around the same temperature seems to suggest the existence of some correlation between these two, which leads us to the following tentative interpretation.

It is considered that there are a number of dislocation pile-ups in plastically deformed metals. After the release of applied stress, dislocations in pile-ups will tend to escape from them so as to assume more energetically stable arrangements. It may be assumed that there are two kinds of pile-ups, i.e. in one of them the dislocations prefer a forward motion and in the other, a backward motion. Here "forward" refers to the direction of the previous deformation and "backward" to the opposite. The experimentally observed creep recovery is always a consequence of both kinds of dislocation motions. For the forward motion of dislocations to occur after the stress release, it is necessary that the barrier for the backward motion is more effective than that for the forward motion. In the previous paper ${ }^{(5)}$, it was proposed that the forward barriers which are overcome by the forward motion of dislocations for the reversed creep recovery to occur might be subboundaries which were numerous in specimens annealed at a relatively lower temperature of about $250^{\circ} \mathrm{C}$ after drawing.

On the other hand, it is naturally considered that not only dislocations but also point defects are inhomogeneously distributed in cold worked metals. The density of point defects may be much higher in the

(9) W. Lems : Physica, 28 (1962), 445.

(10) W. Loms : Physica, 30 (1964), 445. 
regions where dislocations have passed, since point defects are produced by the movement of dislocation jogs. Thus dislocations which jumped out from the pile-up to the backward direction are met by many point defects and are pinned down there. However, those jumped out to the forward direction have less chances to be caught by point defects, because the forward region is less frequently swept by dislocations during plastic deformation. Thus the dislocations having moved forwards will be able to oscillate more freely than in a pile-up. Hence, the simultaneous occurrence of reversed creep recovery and the decrease in elastic modulus may consistently be explained.*

\section{Conclusion and Summary}

(1) The modulus recovery of the $700^{\circ} \mathrm{C}$ annealed specimen was quite similar to that observed by Lems.

(2) There was no clear indication which suggested a correlation between the modulus recovery (measured at $-155^{\circ} \mathrm{C}$ ) and the creep recovery in this specimen.

(3) The modulus recovery of the $250^{\circ} \mathrm{C}$ annealed specimen showed a quite different behavior from that of the $700^{\circ} \mathrm{C}$ annealed one.

(4) The feature of the creep recovery of this specimen showed a peculiar behavior and seemed to have a correlation with that of the modulus recovery. The characteristic features of both modulus recovery and creep recovery was explained in consideration of the nature of dislocation pile-ups and the inhomogeneous distribution of point defects in the deformed specimen which had been annealed at relatively low temperatures and contained numerous subboundaries.

\section{Acknowledgments}

One of the authors (M.K.) expresses his deep appreciation to Prof. M. Hirabayashi for his continued interest in this work and to the Sakkokai Foundation for its financial support.

\footnotetext{
* From the present results on the elastic modulus recovery, it is predictable that the annealing behaviors of the Bordoni peak, the Niblett-Wilks peak and other relaxation components at very low temperatures may be considerably different in the two specimens annealed at different temperatures prior to deformation.
} 